\title{
Thismia belumensis (Thismiaceae), a remarkable new species from The Royal Belum State Park, Gerik, Perak, Peninsular Malaysia
}

\author{
Mat Yunoh Siti-Munirah', Zainol Suhaimi-Miloko², \\ Mohammad Ismail Zubir Ahmad ${ }^{3}$
}

I Forest Research Institute Malaysia, 52109, Kepong, Selangor, Malaysia 2 No 49, Taman Desa Damai, 33300, Gerik, Perak, Malaysia 3 The Royal Belum State Park, Perbadanan Taman Negeri Perak, Hentian Amanjaya Royal Belum, Pulau Banding, 33200, Gerik, Perak, Malaysia

Corresponding author: Mat Yunoh Siti-Munirah (sitimunirah@frim.gov.my)

Academic editor: Sandy Knapp | Received 5 October 2020 | Accepted 12 January 2021 | Published 18 February 2021

Citation: Siti-Munirah MY, Suhaimi-Miloko Z, Zubir Ahmad MI (2021) Thismia belumensis (Thismiaceae), a remarkable new species from The Royal Belum State Park, Gerik, Perak, Peninsular Malaysia. PhytoKeys 172: 121-134. https://doi.org/10.3897/phytokeys.172.59336

\begin{abstract}
This report describes Thismia belumensis Siti-Munirah \& Suhaimi-Miloko, a novel species of achlorophyllous herb discovered in the Royal Belum State Park, Peninsular Malaysia. This new species is unlike any previously described species of Thismia. In particular, T. belumensis possesses a unique annulus, which has been expanded and modified into a cucullate (hood-like) structure. This structure covers the apical floral tube and has an opening on one side facing a thickened part of the annulus, and the off-centre floral aperture confers a zygomorphic symmetry to the flower, indicating T. belumensis is more similar to Thismia labiata J.J.Sm. This morphological detail makes this new species distinct from all other described species of Thismia. In this report, we provide descriptions, illustrations, colour plates, and the provisional conservation status of Thismia belumensis.
\end{abstract}

\section{Keywords}

Conservation status, endemic, Peninsular Malaysia, Perak, Thismia belumensis, zygomorphic 


\section{Introduction}

Thismia Griff. (Thismiaceae) is a genus of small mycoheterotrophic herbs, currently comprising approximately 80-90 species (Dančák et al. 2020a; Nuraliev et al. 2020; Shepeleva et al. 2020). Plants of this genus are primarily distributed in the tropical regions of Asia, Australia, and South America, and extend into the subtropical and temperate regions of Japan, New Zealand, Australia, and the USA (Merckx et al. 2013; Dančák et al. 2020b). In Peninsular Malaysia, little is known about most Thismia species as they are normally only noticeable when in flower, and the flowers can be small, fragile, and ephemeral. The plant is also easily dehydrated and can rapidly degrade if taken from its original habitat. Studying these plants is challenging, as careful and rapid care must be taken to retain the plant's true appearance and structure. Due to their fast degradation, Thismia species cannot be handled and studied like typical pressed herbarium specimens. Therefore, to obtain accurate images of their morphology, they must be dissected in the field, or immediately stored in an airtight container for transport to the research station for further investigation, or immediately preserved in $70 \%$ ethanol.

For many decades, the knowledge of Thismia species in Peninsular Malaysia has not been updated, with Jonker (1948) the most recent taxonomic. Seventy years later, in 2018, a new species description was published - Thismia kelantanensis SitiMunirah (Siti-Munirah 2018). Since then, two more species have been described Thismia domei Siti-Munirah and Thismia terengganuensis Siti-Munirah (Siti-Munirah and Dome 2019). It is likely that more novel species will be discovered in the future (Siti-Munirah and Dome 2019). The most recent publication describing Malaysian Thismia is from Sarawak (Borneo) and describes Thismia minutissima Dančák, Hroneš \& Sochor (Dančák et al. 2020a). Overall, throughout Malaysia, there are currently approximately 30 Thismia species, of which - including T. belumensis, described in this report, -14 of these are found in Peninsular Malaysia. These are: Thismia alba Holttum ex Jonker, Thismia arachnites Ridl., Thismia aseroe Becc., Thismia chrysops Ridl., Thismia clavigera F. Muell., Thismia crocea (Becc.) J.J.Sm, Thismia domei Siti-Munirah \& Dome, Thismia fumida Ridl., Thismia grandiflora Ridl., Thismia javanica J.J. Sm, Thismia kelantanensis Siti-Munirah, Thismia racemosa Ridl. and Thismia terengganuensis Siti-Munirah (Jonker 1948; Siti-Munirah 2018; Siti-Munirah and Dome 2019).

The Thismia species described here was first discovered in 2017 by Mr. SuhaimiMiloko during a guided nature tour in the Royal Belum State Park (SP), Perak, Peninsular Malaysia (Map 1). The majority of the Royal Belum SP is covered by pristine primary tropical rainforest and was established as a 117,500 ha forest park in 2007 by the Perak state government. Royal Belum SP is the second-largest protected area in Peninsular Malaysia - after the Taman Negara (431,435 ha) (Schwabe et al. 2015). The new species of Thismia was discovered in the Sungai Gadong forest area, in the southern part of the Royal Belum SP. This location is also an important habitat of Rafflesia azlanii Latiff \& Wong, and $R$. cantleyi Solms, which possess the world's largest 


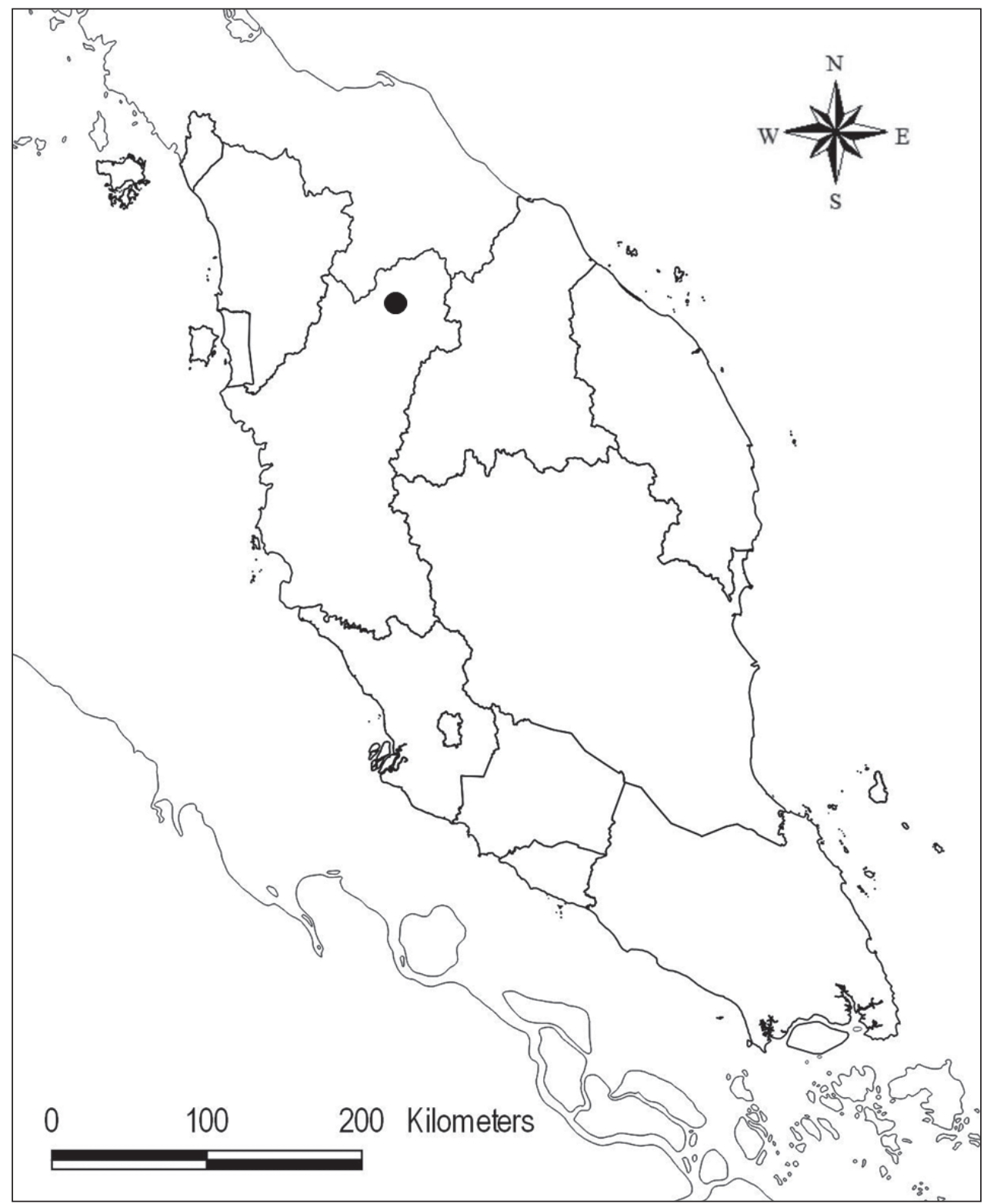

Map I. Map of Peninsular Malaysia indicating the location of Thismia belumensis (•).

flowers (Siti-Munirah 2012, 2020). In October 2019, we visited the site, and several specimens of the new Thismia species were collected for taxonomic study. After careful examination, some novel characteristics of the annulus and tepals were identified in the specimens. These traits formed a unique combination of characteristics that did not match any described species of Thismia. Hence, it is described here as a new species. 


\section{Materials and methods}

This study is based on material collected by M.Y. Siti-Munirah in October 2019 from The Royal Belum SP, Gerik. The specimens were preserved in $70 \%$ ethanol in the Kepong (KEP) herbarium collections. Morphological characteristics were studied using a stereomicroscope and high-resolution macro photography. Measurements were taken from both living and alcohol-preserved material. The specimen details were thoroughly compared with drawings and descriptions in the protologues of Thismia species worldwide.

\section{Taxonomic account}

Thismia belumensis Siti-Munirah \& Suhaimi-Miloko, sp. nov. urn:Isid:ipni.org:names:77215193-1

Figs $1-3$

Diagnosis. Most similar to Thismia labiata J.J.Sm. but differing in the floral tube partially covered by a massively expanded cucullate bilabiate annulus, longer outer tepals appendage, obovate to spathulate rather than linear to filiform inner tepals and the supraconnective apex curved outwards like a skirt rather than straight.

Type. Malaysia. Peninsular Malaysia: Perak, Gerik Distr., Royal Belum State Park, ca. 290 m alt., 22 October 2019, M.Y. Siti-Munirah FRI 94758 (holotype: KEP!, spirit collection, No. barcode 279998).

Description. Terrestrial, achlorophyllous, brownish-whitish-green herbs up to $8 \mathrm{~cm}$ tall. Roots vermiform white-brownish. Stems erect (sometimes ascending), unbranched, $2-4 \mathrm{~cm}$ long, glabrous. Leaves scale-like, simple, translucent white, $5 \mathrm{~mm}$ long, 1-2 mm wide, triangular, apex acute or acuminate, base appressed. Involucral bracts 3, white, up to ca. $1 \mathrm{~cm}$ long, lanceolate, apex acute to acuminate, margin entire, glabrous, base appressed. Pedicel 2-4 mm long (post anthesis). Flowers terminal, zygomorphic, solitary, 5-8 cm long (including appendages); floral tube (hypanthium) 5-7 mm long, 3-6 mm wide, narrowed just above the ovary ca. $3 \mathrm{~mm}$ wide, widest on upper part ca. $6 \mathrm{~mm}$ wide, slightly shorter at one side (lower on the floral aperture side), outer surface verrucose covered with very short minute warts (papillae); basal half green, apical half with 12 dark brown and 12 pale brown (almost translucent) vertical stripes; inner surface smooth without transverse bars and other ornamentation; emerald green and translucent; outer tepals 3 , pale brown each $3 \times$ $2 \mathrm{~mm}$, apex acute, each with forming a distal filiform, tentacle-like appendage, the two on the opposite side of the annulus opening erect and the one below the thickened annulus slender, ca. $1.5-2.5 \mathrm{~cm}$ long, ca. $1 \mathrm{~mm}$ wide, cylindrical, brownish-greenish and sometimes whitish towards the subulate tip; inner tepals 3, brownish to pure white, glabrous (smooth), obovate to spathulate, tightly adpressed and almost completely overlapping the cucullate part of annulus, basally with long and erect appendages, ca. $3 \mathrm{~cm}$ long, brownish-greenish and sometimes whitish towards clavate tip. Annulus expanded and modified into a cucullate (hood-like) structure and thickened part of 


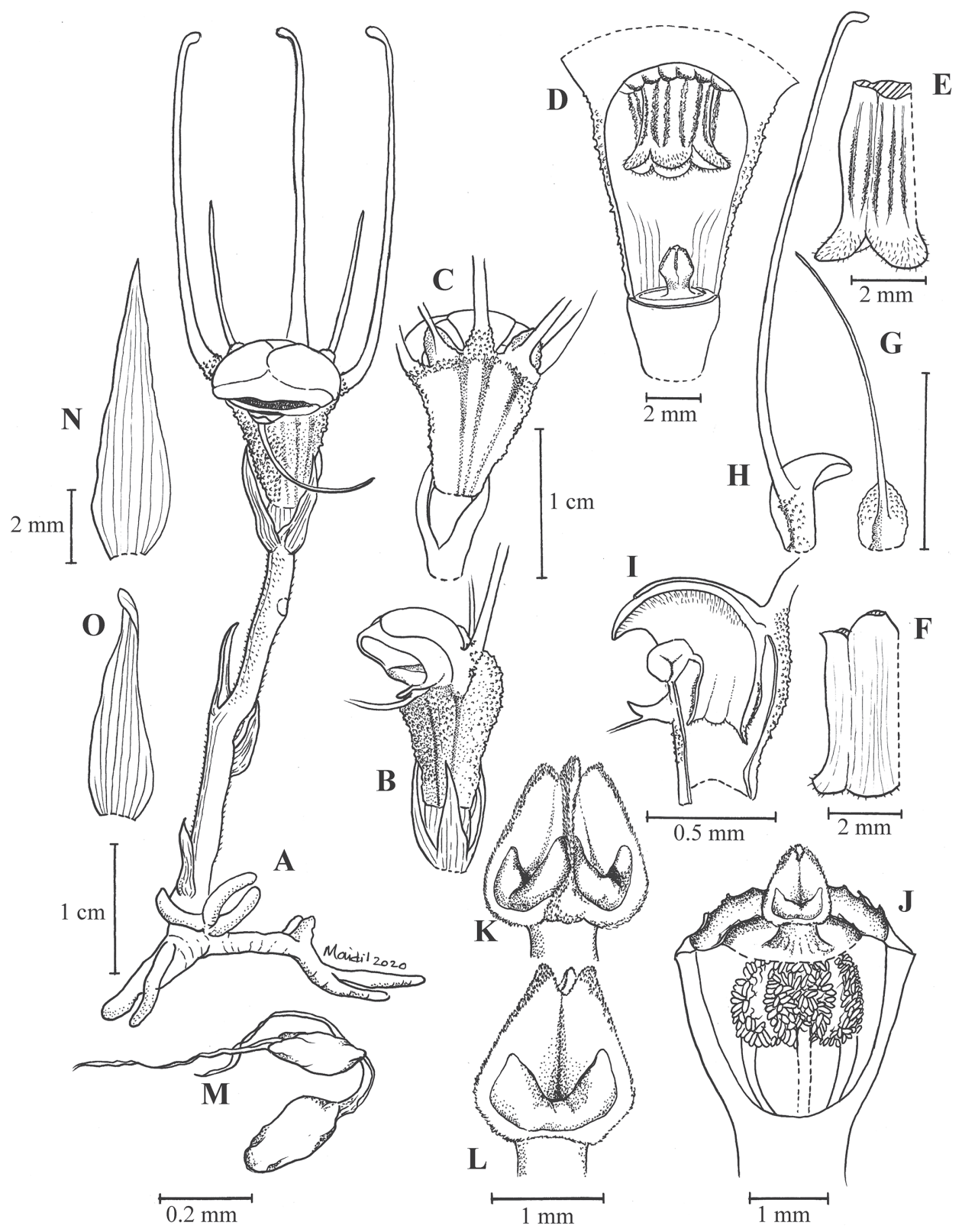

Figure I. Illustration of Thismia belumensis Siti-Munirah \& Suhaimi-Miloko A habit B side view of flower $\mathbf{C}$ back view of flower $\mathbf{D}$ longitudinal section of the floral tube showing pendulous stamen with ovary and stigma $\mathbf{E}$ outer view of stamens $\mathbf{F}$ inner view of stamens $\mathbf{G}$ outer tepal $\mathbf{H}$ inner tepal $\mathbf{I}$ longitudinal section of hood (annulus) and pendulous stamens $\mathbf{J}$ longitudinal section of ovary $\mathbf{K}$ stigma $\mathbf{L}$ pistil $\mathbf{M}$ ovules $\mathbf{N}$ bract $\mathbf{O}$ leaf. All from FRI 94752 \& FRI 94758, drawn by Mohamad Aidil Noordin.

the annulus, the cucullate covering the apical part of the floral tube and forming a downwards floral aperture and facing thickened part of the annulus on one side of the flower; cucullate outer surface white with 3 black lines, glabrous; cucullate inner 
surface white to brownish-peach, covered with numerous white translucent trichomes pointing inwards. Stamens 6, pendent from the apical part of the floral tube; each connective ca. $3.3 \mathrm{~mm}$ long, peach; outer surface with two linear to filiform thecae, each $1.8 \mathrm{~mm}$ long, facing the inner wall of the floral tube; inner surface smooth; supraconnective apex blunt and rounded, curved (like a skirt) outwards, covered with transparent trichomes on margin (apparent only in the living state); lateral appendage, apical appendages and interstaminal glands absent; filaments short, connected to floral tube and annulus. Ovary inferior, unilocular, cup-shaped, ca. $3 \mathrm{~mm} \times 4.7 \mathrm{~mm}$, whitish brown outer surface covered with numerous warts; placentas 3 , bearing numerous ovules; style ca. $0.4 \mathrm{~mm}$ long; stigma triangular-pyramidal, dark greenish, ca. $1.55 \mathrm{~mm}$ long, papillate, unusual whitish thickened part on each surface (sometimes difficult to see), apex truncate (trilobed). Fruit cup-shaped, white or pale brown with white operculum, pedicel not elongated.

Distribution. Endemic to Perak, Peninsular Malaysia. Currently known only from the type locality (Map 1).

Ecology. Lowland dipterocarp forest, under shade, 260-290 m altitude. Flowering from June to October. Thismia belumensis was found growing within tree leaf litter and between the buttress roots of large trees (Fig. 4). Two other Thismia species were also discovered within a radius of about 350 meters, T. javanica and Thismia sp. 1 (see Fig. 5), which is currently suspected by the authors to be Thismia arachnites Ridl., but further examination is still needed. All plants were found close to the walking trail.

Etymology. The species is named after The Royal Belum State Park, the type locality of this species.

Conservation status. Critically Endangered (B1B2ab(iii)). Following the IUCN Standards and Petitions Committee (2019), this species is assessed as critically endangered as it is only known from the type locality and is certainly endemic and rare. Fewer than ten specimens were observed, including flowering and fruiting individuals. Although the locality is within the State Park forest reserve, a protected area, the area is located beside the walking trail, which is a common visiting site for tourists in the Park. The site where T. belumensis was found is currently designated as a Tourist Zone in the Royal Belum State Park Management Plan 2018-2027. All guides can freely bring tourists to the area without special permission from the Perak State Park Corporation. Due to the small size of T. belumensis, it may not be noticed, and so has a high chance of being stepped on. Without official reminders or guidance, the existence of $T$. belumensis might be threatened by ecotourism activities. Thismia belumensis qualifies for CR (B1B2ab(iii)) for its single location, EOO less than $100 \mathrm{~km}^{2}$, and $\mathrm{AOO}$ less than $10 \mathrm{~km}^{2}$. Its habitat quality is also threatened by wild boars (personal observation by Suhaimi-Miloko) and other destructive activities, such as regular visits by tourists to the area. Together, these have the potential to cause a population reduction.

Additional specimen examined. Peninsular Malaysia. Perak: Gerik, Royal Belum State Park, ca. 260 m alt., 22 October 2019, M.Y. Siti-Munirah FRI94752 (KEP, spirit collection, No. barcode 279997). 


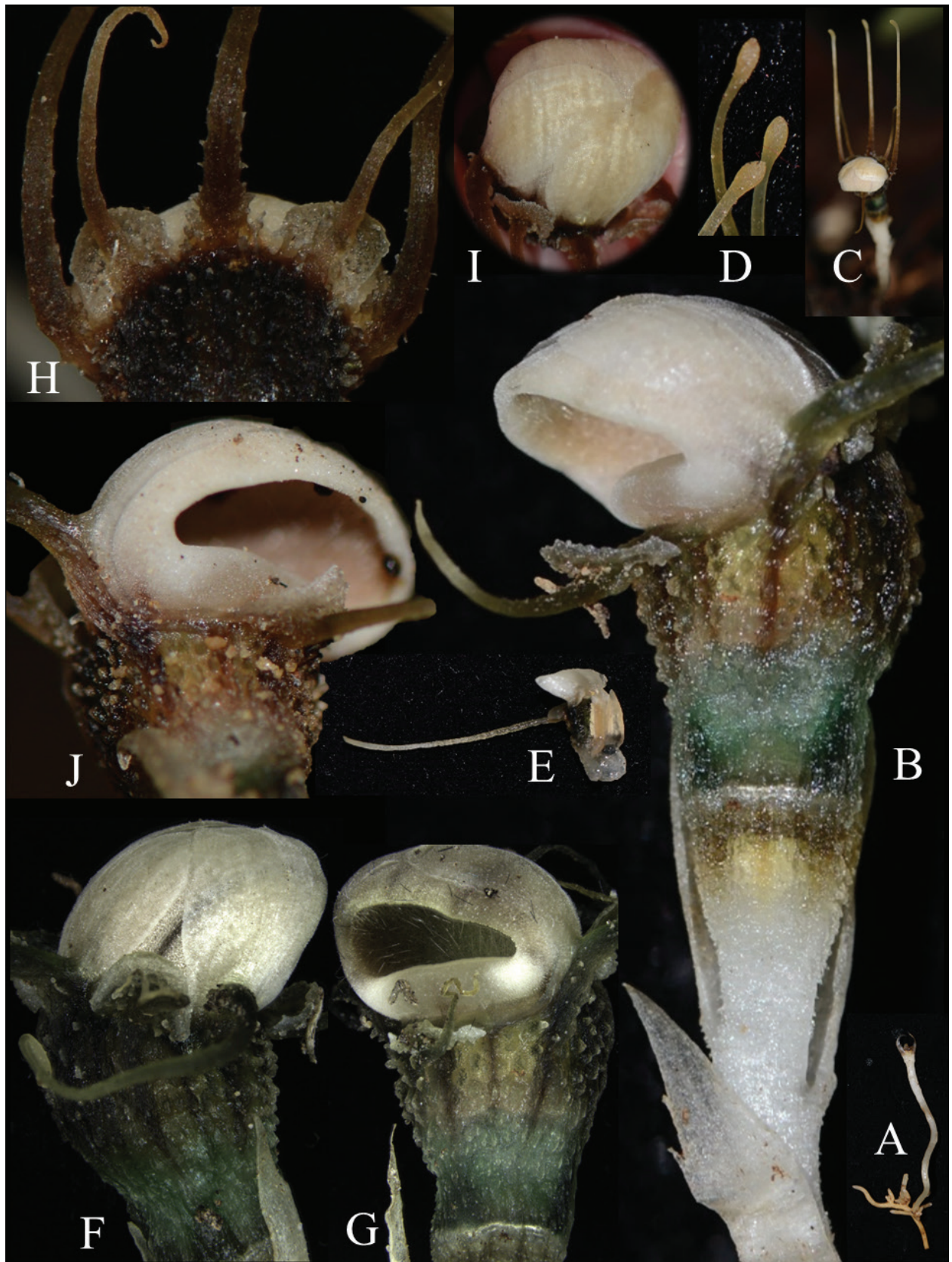

Figure 2. Outer appearance of Thismia belumensis Siti-Munirah \& Suhaimi-Miloko A root and stem B flower from side view $\mathbf{C}$ flower showing the erect tepal appendages of the live plant $\mathbf{D}$ tip of erect tepal appendages $\mathbf{E}$ slender appendage of outer tepal $\mathbf{F}$ side view showing inner tepals overlaying the cucullate structure $\mathbf{G}$ floral tube with the floral aperture of the expanded annulus $\mathbf{H}$ outer tepals alternate with inner tepals, each with distal or dorsal appendage I top view of flower showing inner tepals overlapping on cucullate structure J semi-round shape of the aperture of the annulus (All photos by Siti-Munirah MY, FRI $94752 \&$ FRI 94758). 


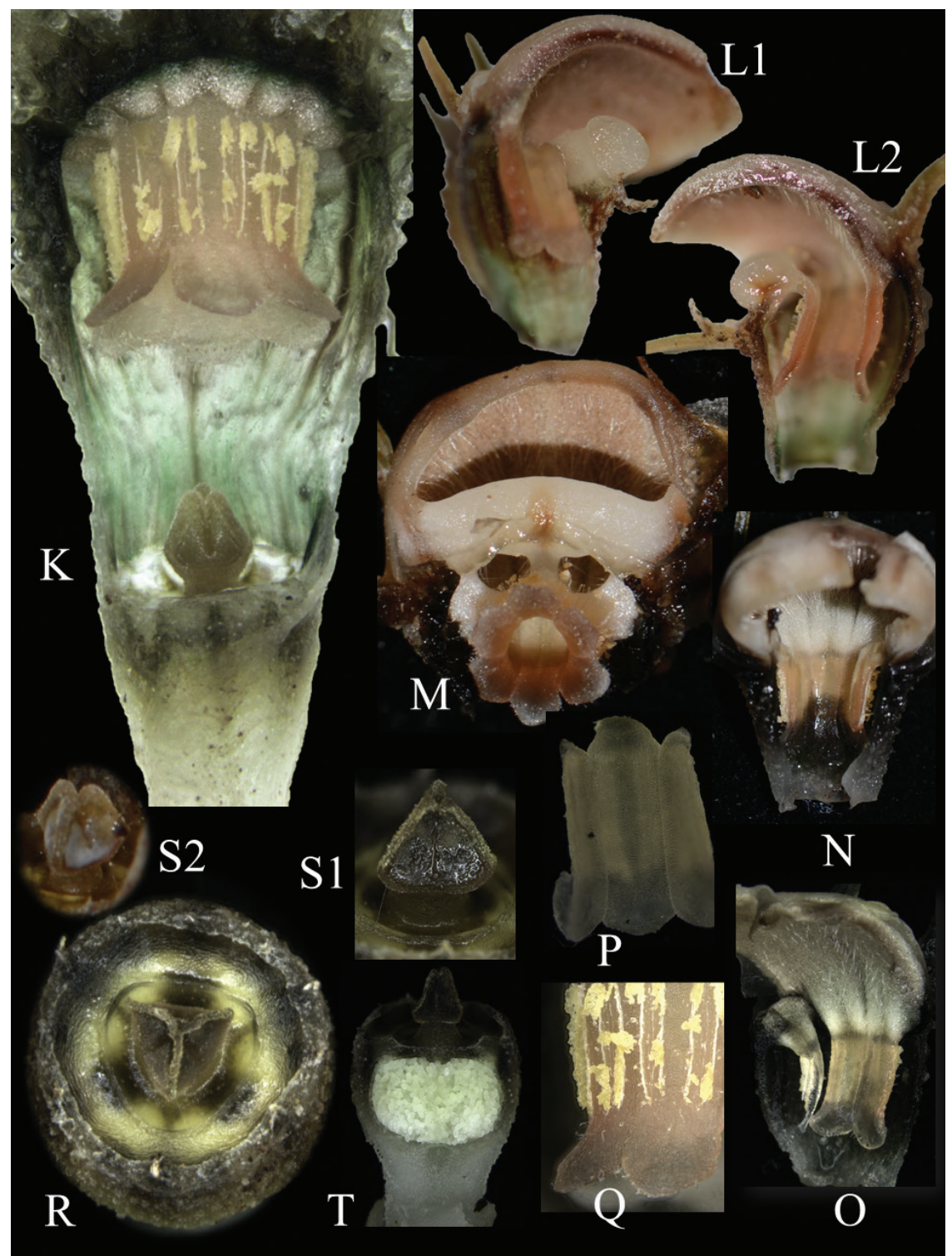

Figure 3. Inner flower appearance of Thismia belumensis Siti-Munirah \& Suhaimi-Miloko K longitudinal section showing the internal parts of flower $\mathbf{L}$ longitudinal section of floral tube and apical part (LI left side L2 right side) showing pendulous stamen attached to the filament, expanded annulus developing a cucullate (hood-like) structure, thickened part of the annulus at one-side, and outer surface of hood overlaid by inner tepals $\mathbf{M}$ transverse section of floral tube at lower part showing the apex of fused pendulous stamen and the floral aperture with the thickened part of the annulus in the centre $\mathbf{N}$ inner view of stamens and filament attached to the expanded annulus, which is covered with white trichome hairs $\mathbf{O}$ inner view of two stamens and hood inner surface $\mathbf{P}$ stamen (from inner view) $\mathbf{Q}$ stamen displaying linear to filiform thecae (outer view) and supraconnective apex curved outwards $\mathbf{R}$ top view of ovary and stigma $\mathbf{S}$ stigma from side view (SI shows triangular-pyramidal $\mathbf{S 2}$ shows whitish part on surface) T cross-section of ovary showing young seeds (All photos by Siti-Munirah MY, FRI 94752 \& FRI 94758). 


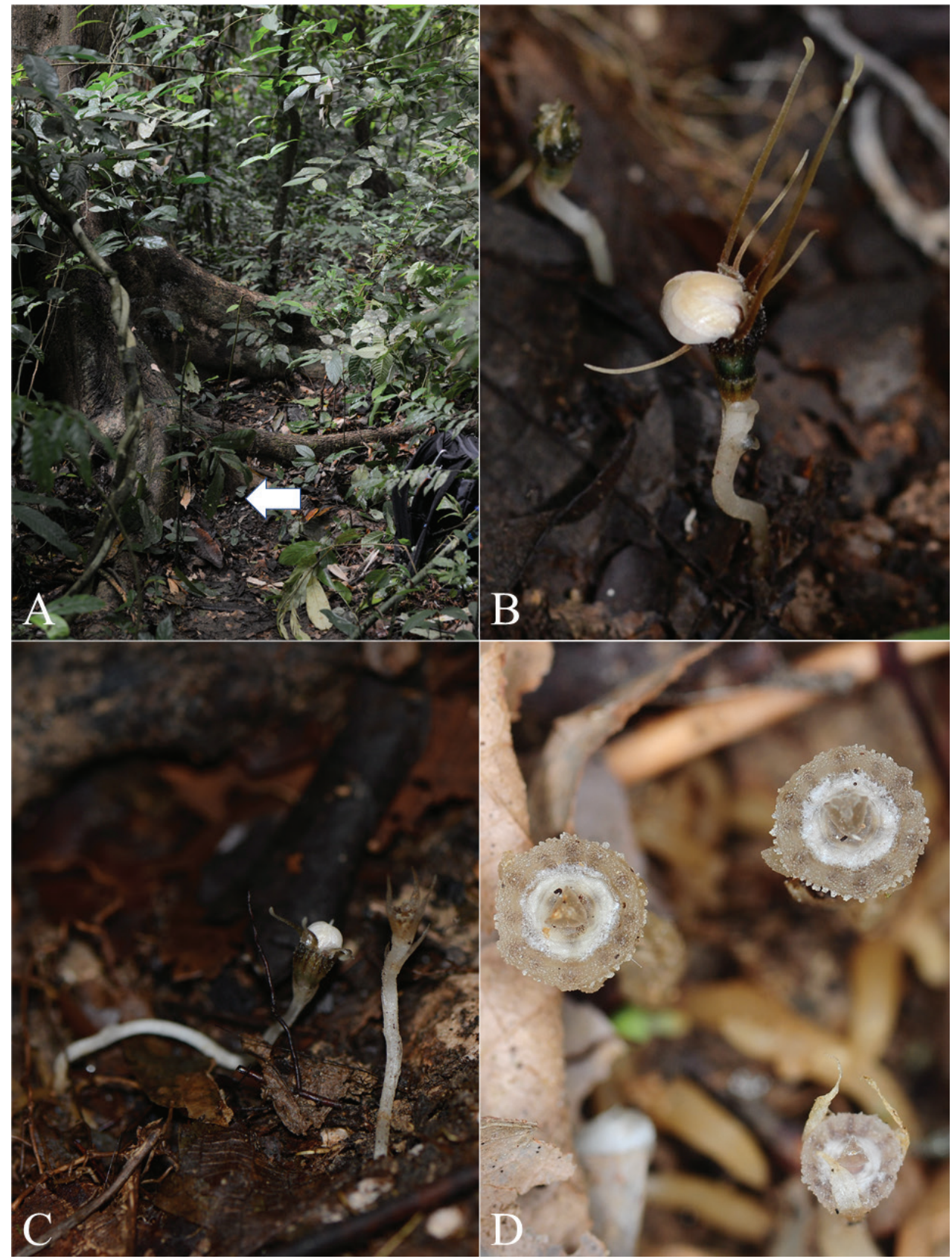

Figure 4. Thismia belumensis Siti-Munirah \& Suhaimi-Miloko A habitat B T. belumensis growing in leaf litter, FRI $94758 \mathbf{C}$ habit of the young flowering plant and the young fruit of T. belumensis $\mathbf{D}$ fruits of T. belumensis, in-situ (Photos by A-C Siti-Munirah MY D Suhaimi-Miloko Z). 


\section{Discussion}

This report represents the first description of a novel, notable, and very rare plant T. belumensis - from The Royal Belum SP, Perak, Malaysia. This new species is significantly different from other "fairy lantern" species found in the Malay Peninsula and Borneo. Morphologically, T. belumensis is strikingly different from other species by its annulus structure, tepals with an appendage, and floral colours. Nuraliev et al. (2020), describe the annulus as a large, fleshy ring-like structure. However, T. belumensis possesses an unusual form of annulus. T. belumensis is characterised by most of the annulus being hugely expanded and modified into a cucullate (hood-like) structure covering the apical part of the floral tube, with an aperture on one side facing a thickened part of annulus. The off-centre floral aperture changes the flower symmetry to bilateral, or zygomorphic. In this way, T. belumensis is unlike all other known Thismia species in Malaysia, which have radially-symmetrical flowers in which the annulus, when developed, has an apical aperture (Fig. 5).

Thismia belumensis is morphologically similar to Thismia labiata J.J.Sm. (Smith 1927) and Thismia sahyadrica Sujanapal, Robi \& Dantas (Sujanapal et al. 2017). All three species share several unique characters, such as a zygomorphic flower with a sideways facing annulus orifice (T. belumensis and T. labiata), filiform and linear thecae (T. belumensis, T. labiata and T. sahyadrica), a curved supraconnective (T. belumensis and T. sahyadrica), and a lack of a lateral appendage and interstaminal glands (T. belumensis, T. labiata and T. sahyadrica). However, most other morphological characteristics of T. belumensis are unique. Both T. belumensis and T. labiata have two types of tepals and appendages; however, these differ between the species. Thismia belumensis tepals are unique for the false mitre formed by the inner tepal (loose mitre, if the cucullate structure is absent) (Fig. 2F). With the presence of the cucullate structure, the inner tepals of $T$. belumensis, therefore, completely overlay the outer surface of the cucullate structure (Fig. 2F, I). In T. labiata, the annulus forms a labiate structure - a thick, fleshy, upper lip bent over the opening of the floral tube (Fig. 6A), with one inner and two outer tepals of the back of this lip (Fig. 6A, B). There are two more inner tepals between the two lips - one on either side of the flower - and the third outer tepal is inserted in the middle of the lower lip (Fig. 6A, B). In contrast, the outer tepal of T. belumensis appears upright (Figs 1G, 2H) with the inner tepals (with erect appendages, Fig. 2C), and with only one slender tepal and appendage (Fig. 2E), attached below the thickened part of the annulus (Figs 2B, 3L2). Both types of tepal in T. belumensis have their own form of appendage, and both were much longer compared to appendages of T. labiata (Figs 1G, H, 6B-D). Based on other records, the morphology of the outer tepals (also call lateral tepals, Smith 1927) and the appendage of T. labiata are more similar to the tepals of T. sahyadrica. Additionally, while the inner tepals of T. labiata are linear to filiform (appearing as a long appendage without a tepal, Fig. 6A, B), this characteristic is different in T. belumensis, inner tepals obovate to spathulate with a ca. $3 \mathrm{~cm}$ long appendage (Figs 1H, 2F). Furthermore, the T. belumensis stigma morphology is nearly similar to T. labiata but completely different from T. sahyadrica. Finally, all 


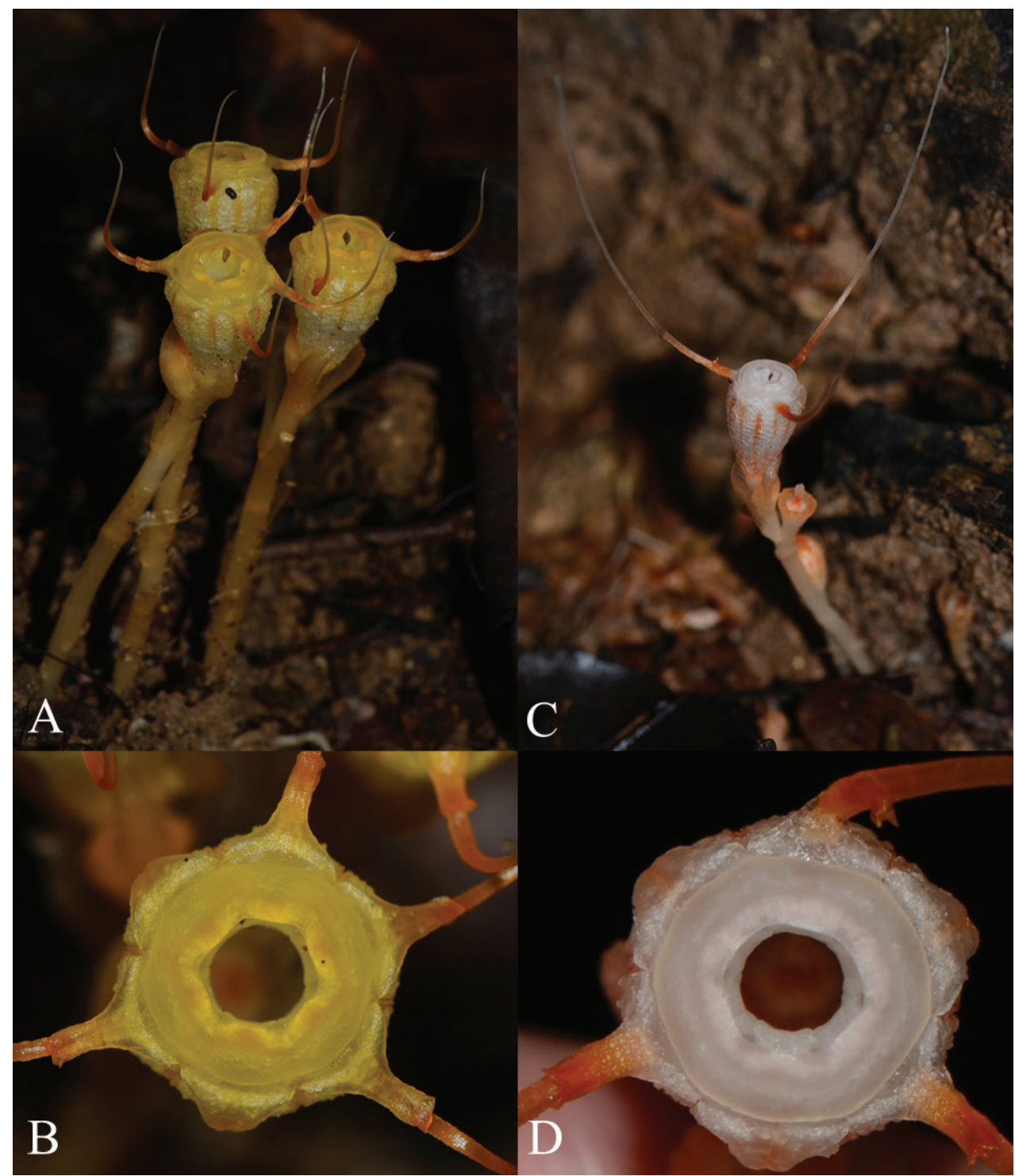

Figure 5. Other Thismia species found in the same area as T. belumensis $\mathbf{A}$ Thismia sp. 1, undescribed species $\mathbf{B}$ top view of Thismia sp1. showing the annulus and tepals $\mathbf{C}$ Thismia javanica $\mathbf{D}$ top view of T. javanica showing the annulus and tepals (symmetrical flower) (All photos by Siti-Munirah MY).

three species have vermiform roots, with both $T$. belumensis and T. labiata possessing simple vermiform roots with and single axis. By contrast, T. sahyadrica possesses vermiform roots with clustering at the base of many stems. In summary, there is no doubt that $T$. belumensis is unique, but morphologically closest to T. labiata - especially with its zygomorphic flower. However, T. belumensis has certain other morphological characteristics that indicate a different position and relatives in Thismia. 


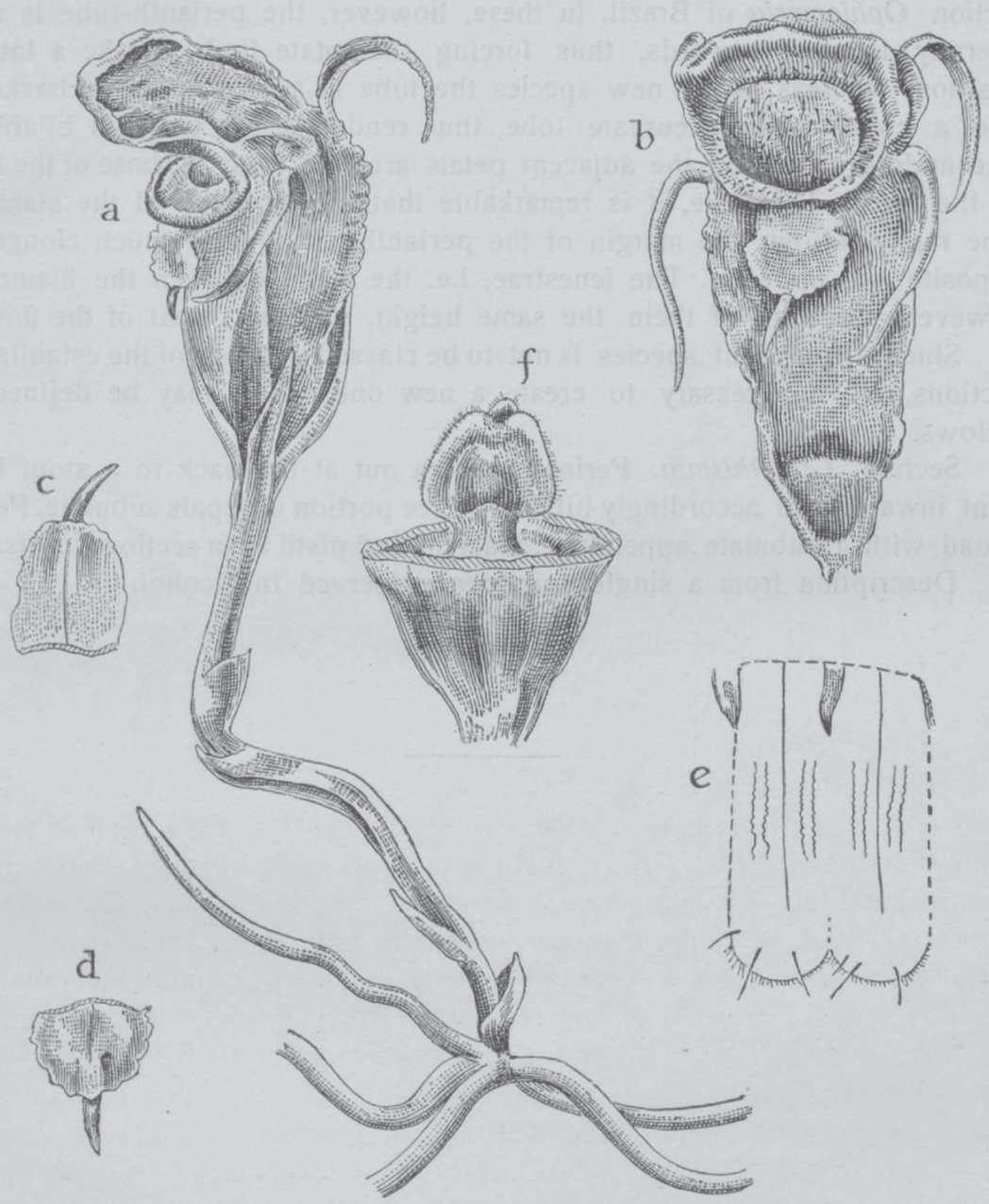

Thismia labiata J. J. S.

a. Planta florens; b. Flos antice visus; c. Petalum laterale; d. Petalum impar; e. Pars tubi staminalis; f. Pistillum.

Figure 6. Drawing from the original protologue of Thismia labiata (Smith 1927: 221) A plant blossoming B flower in front view $\mathbf{C}$ lateral tepal (outer tepal) $\mathbf{D}$ odd tepal (outer tepal) $\mathbf{E}$ part of the stamen tube $\mathbf{F}$ pistil.

As discussed above, T. belumensis resembles T. labiata (Fig. 6) - a Sumatran (Indonesia) species for which own section Labiothismia was proposed (Smith 1927) - in its growth and overall appearance (i.e., bilaterally symmetrical flowers and stamens with elongated thecae). However, it must be noted that the Labiothismia section is not recognised by Kumar et al. (2017), which instead places T. labiata in subsection Brunonithismia. 
Thismia belumensis also belongs to subgenus Thismia and potentially belongs to subsection Brunonithismia along with T. labiata (Kumar et al. 2017). However, the accuracy of this placement is uncertain, and T. belumensis probably cannot be included in subgeneric classification proposed by Kumar et al. (2017). Further investigation is greatly needed.

Thismia belumensis could also potentially belong in section Glaziocharis (Shepeleva et al. 2020). The most prominent trait of species in this section is an absence of the lateral appendage, but other traits also suggest this placement; for example, the presence of a false mitre and the absence of transverse bars inside the hypanthium, both observed in T. belumensis. The absence of interstaminal glands and a lateral appendage (also called a wing-like appendage) suggest that all three species' ( $T$. belumensis, T. labiata and T. sahyadrica) are closely related to species forming clade 1 in Shepeleva et al. (2020). Whether they are encapsulated within this section or form a distinct sister group must be resolved by phylogeny studies.

In conclusion, the significant differences and unique traits of T. belumensis - i.e., the floral tube detail, the annulus structure, the morphology of the tepals and appendages, and the stamens - compared to other Thismia species worldwide, strongly supports the recognition of this remarkable new species. Further study of this new species, such as, its life cycle, pollination system, and including molecular analysis, is crucial to gain new knowledge and understanding of the phylogenetic and biogeographic of Thismia of the world.

\section{Acknowledgements}

This research was carried out as part of the Flora of Peninsular Malaysia Project (FPM) at the Forest Research Institute Malaysia (FRIM), Kepong, funded by the Ministry of Energy and Natural Resources of Malaysia under the $11^{\text {th }}$ Malaysian Plans (SPPII No. P23085100018003). We would like to thank the Royal Belum Park Corporation for giving permission for the botanical trip and all RBSP staff involved in the field and members of FPM. We also thank Mohamad Aidil Noordin for the botanical drawings. We are grateful to Francis $\mathrm{Ng}$ for discussion and comments on the manuscript, to all the reviewers, Martin Dančák, Michal Hroneš and Michal Sochor, for constructive comment in improving the manuscript, Wendy SY Yong for assisting in assessing the conservation status and Mohd Faizal Mat Tahir for his courage and great assistance during the preparation of the manuscript.

\section{References}

Dančák M, Hroneš M, Sochor M (2020a) Thismia minutissima (Thismiaceae), a remarkable new mycoheterotrophic species from Sarawak, Borneo. Kew Bulletin 75(2): e29. https:// doi.org/10.1007/s12225-020-09886-4

Dančák M, Hroneš M, Sochor M (2020b) Thismia ornata and T. coronata (Thismiaceae), two new species from Sarawak, Borneo. Willdenowia 50(1): 65-76. https://doi.org/10.3372/ wi. 50.50106 
Jonker FP (1948) Burmanniaceae. In: van Steenis CGGJ (Ed.) Flora Malesiana. Leiden, Noordhoff-Kolf, series 1, 4: 13-26.

Kumar P, Gale SW, Li JH, Bouamanivong S, Fischer GA (2017) Thismia nigricoronata, a new species of Burmanniaceae (Thismieae, Dioscoreales) from Vang Vieng, Vientiane Province, Laos, and a key to subgeneric classification. Phytotaxa 319(3): 225-240. https://doi. org/10.11646/phytotaxa.319.3.2

Merckx VSFT, Freudenstein JV, Kissling J, Christenhusz MJM, Stotler RE, Crandall-Stotler B, Wickett N, Rudall PJ, Maas van de Kamer H, Maas PJM (2013) Taxonomy and classification. In: Merckx VSFT (Ed.) Mycoheterotrophy: the biology of plants living on fungi. Springer, New York, 19-101. https://doi.org/10.1007/978-1-4614-5209-6_2

Nuraliev MS, Yudina SV, Shepeleva EA, Truong BV, Do TX, Beer AS, Remizowa MV (2020) Flower structure in Thismia (Thismiaceae, Dioscoreales): New insights from anatomy, vasculature and development. Botanical Journal of the Linnean Society: boaa066. https://doi. org/10.1093/botlinnean/boaa066

Schwabe K, Carson RT, DeShazo JR, Potts MD, Reese AN, Vincent JR (2015) Creation of Malaysia's Royal Belum State Park: A Case Study of Conservation in a Developing Country. Journal of Environment \& Development 24(1): 54-81. https://doi. org/10.1177/1070496514551173

Shepeleva EA, Schelkunov MI, Hroneš M, Sochor M, Dančák M, Merckx VSFT, Kikuchi IA, Chantanaorrapint S, Suetsugu K, Tsukaya H, Mar SS, Luu HT, Li H-Q, Logacheva MD, Nuraliev MS (2020) Phylogenetics of the mycoheterotrophic genus Thismia (Thismiaceae: Dioscoreales) with a focus on the Old World taxa: delineation of novel natural groups and insights into the evolution of morphological traits. Botanical Journal of the Linnean Society 193(3): 287-315. https://doi.org/10.1093/botlinnean/boaa017

Siti-Munirah MY (2012) Raffesia blooms in Royal Belum. Conservation Malaysia 16: 6-9.

Siti-Munirah MY (2018) Thismia kelantanensis (Thismiaceae), a new species from Kelantan, Peninsular Malaysia. Kew Bulletin 73(3): e42. https://doi.org/10.1007/s12225-018-9767-0

Siti-Munirah MY (2020) Notes on a ten-perigoned Rafflesia azlanii from the Royal Belum State Park, Perak, Peninsular Malaysia. Malayan Nature Journal 72(1): 11-17.

Siti-Munirah MY, Dome N (2019) Thismia domei and T. terengganuensis (Thismiaceae), two new species, and T. javanica, a new record from Terengganu, Peninsular Malaysia. PhytoKeys 124: 123-137. https://doi.org/10.3897/phytokeys.124.34728

Smith JJ (1927) An interesting New Thismia. Bulletin du Jardin botanique de Buitenzorg, sér. 3 9: 220-222.

IUCN Standards and Petitions Committee (2019) Guidelines for Using the IUCN Red List Categories and Criteria. Version 14. Prepared by Standards and Petitions Committee. http://www.iucnredlist.org/documents/RedListGuidelines.pdf

Sujanapal P, Robi AJ, Dantas KJ, Sumod M, Merckx VSFT (2017) Thismia (Thismiaceae): The first record of the mycoheterotrophic genus to the flora of India with a new species revealing the phytogeographical significance of Western ghats. Blumea 62(2): 97-102. https:// doi.org/10.3767/blumea.2017.62.2.04 